Review Article

\title{
Recent Developments of Photovoltaics Integrated with Battery Storage Systems and Related Feed-In Tariff Policies: A Review
}

\author{
Angel A. Bayod-Rújula, ${ }^{1}$ Alessandro Burgio, ${ }^{2}$ Zbigniew Leonowicz, ${ }^{3}$ Daniele Menniti, ${ }^{2}$ \\ Anna Pinnarelli, ${ }^{2}$ and Nicola Sorrentino ${ }^{2}$ \\ ${ }^{1}$ Department of Electrical Engineering, University of Zaragoza, Zaragoza, Spain \\ ${ }^{2}$ Department of Mechanical, Energy and Management Engineering, University of Calabria, Rende, Italy \\ ${ }^{3}$ Wroclaw University of Science and Technology, Wroclaw, Poland
}

Correspondence should be addressed to Alessandro Burgio; alessandro.burgio@unical.it

Received 2 August 2016; Accepted 16 January 2017; Published 16 March 2017

Academic Editor: Cheuk-Lam Ho

Copyright ( 2017 Angel A. Bayod-Rújula et al. This is an open access article distributed under the Creative Commons Attribution License, which permits unrestricted use, distribution, and reproduction in any medium, provided the original work is properly cited.

\begin{abstract}
The paper presents a review of the recent developments of photovoltaics integrated with battery storage systems (PV-BESs) and related to feed-in tariff policies. The integrated photovoltaic battery systems are separately discussed in the regulatory context of Germany, Italy, Spain, United Kingdom, Australia, and Greece; the attention of this paper is focused on those integrated systems subject to incentivisation policies such as feed-in tariff. Most of the contributions reported in this paper consider already existing incentive schemes; the remaining part of the contributions proposes interesting and novel feed-in tariff schemes. All the contributions provide an important resource for carrying out further research on a new era of incentive policies in order to promote storage technologies and integrated photovoltaic battery systems in smart grids and smart cities. Recent incentive policies adopted in Germany, Italy, Spain, and Australia are also discussed.
\end{abstract}

\section{Introduction}

In the last decade, the incentivisation of renewable source generation systems has received significant appreciation. The International Energy Agency (IEA) [1] calculates that subsidies granted to renewable energy worldwide amount to $\$ 135$ billion in 2014 with an average growth rate of $25 \%$ in 2008. In 2014, Germany, the United States, and Italy hold $50 \%$ of the total of subsidies and $85 \%$ of the first 10 countries. After such a significant economic effort, from 2006 to 2015, the world total RES installed power doubled.

Figure 1 shows the global historical trend of power from installed renewable sources in the world in the last decade; the lower line indicates the percentage of power from photovoltaic sources. Figure 2 shows how power from renewable sources is divided between different continents. It is worth noting that Eurasia includes Armenia, Azerbaijan, Georgia, the Russian Federation, and Turkey. As clearly explained by IRENA in [2], smart grid technologies have facilitated the exploitation of renewable energy sources mainly by increasing grid flexibility. Furthermore, smart grid technologies have also favoured the integration of distributed renewable generation in transmission and distribution electric grids, simultaneously reducing the investment needs for operating existing infrastructures. The profound implications of smart grid technologies on transmission and distribution electric grids have a relevant and strategic importance given that IRENA (International Renewable Energy Agency 2013) estimates that these electric grids will account for almost half of the power sector investment until 2035.

The financial support for renewable source generation systems has significantly reduced the costs of renewable energy; however, since these costs continue, it is hoped that the renewables industry will soon survive without subsidies. It is not reasonable to think that an incentivisation policy can last forever; in fact, it should create and support the market in its initial life phase and then the market should be self-sustaining. 


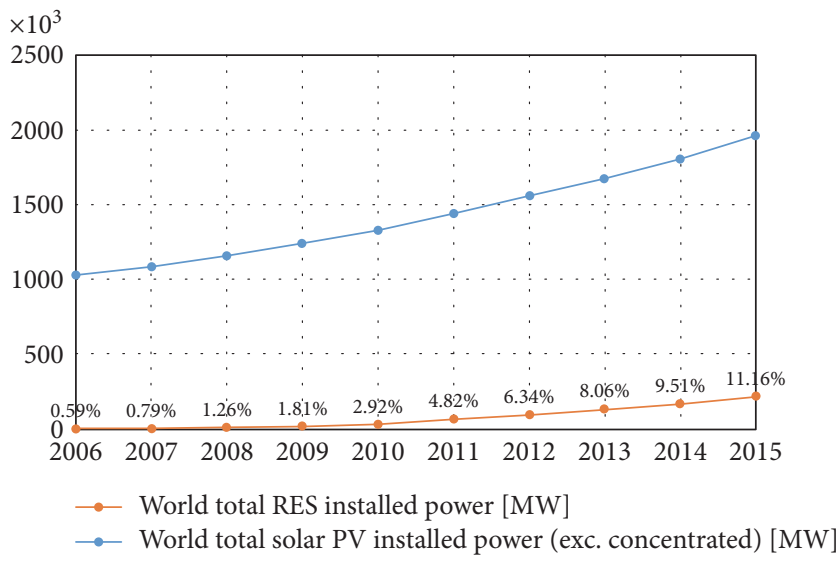

FIGURE 1: World total RES and solar PV installed power in MW in 2006-2015, IRENA statistic 2016.

The tariff of an incentivisation scheme for the exploitation of renewable energy sources should be opportunely determined and, above all, be reasonable, given that financial support for renewable technologies is substantially paid by hardworking families and businesses via their electricity bills. In this connection, Pyrgou et al. [3] discuss the future of the feed-in tariff scheme in Europe; in particular, they exclusively study the case of photovoltaics and examine the regulatory and policy framework of the feed-in tariff scheme, specifically its effect on both the electricity pricing and the local and European renewable energy source markets.

In many countries, the value of the incentivising tariff is typically determined by the National Government considering the type of renewable source (solar, wind, and biomass) and the technical and economic parameters (size, investment, and cost) in order to guarantee certain repayment for those who operate the investment. It is evidently a political issue, and, as often is the case, opinions relating to it can be distinctly contrasting, as in the case of the economist and expert Darwall who states in [4] that renewable subsidies destroyed the UK electricity market. Considered by many people as a climate sceptic, Darwall believes that when politicians decided to impose renewables, they intentionally did not wanted to consider the entirely predictable destruction of the electricity market as a consequence of their policies. On the contrary, the politicians were convinced that the world should have adapted to their preferred generation technology.

Criticism of the effects of social welfare of policies enacted by countries to support the exploitation of renewable sources is not, however, the object of this study. Instead, this study simply seeks to address the case study of integrated battery storage photovoltaic systems. Therefore, in this study, the two technologies for smart grids, namely smart inverters and end user level distributed storage, and photovoltaic plants for the distributed generation of energy from renewables converge.

The contributions of the different authors mentioned in the present work discuss PV-BESs such as those illustrated in Figure 3 in the regulatory context of Germany, Italy, Spain, the United Kingdom, Australia, and Greece. More precisely,

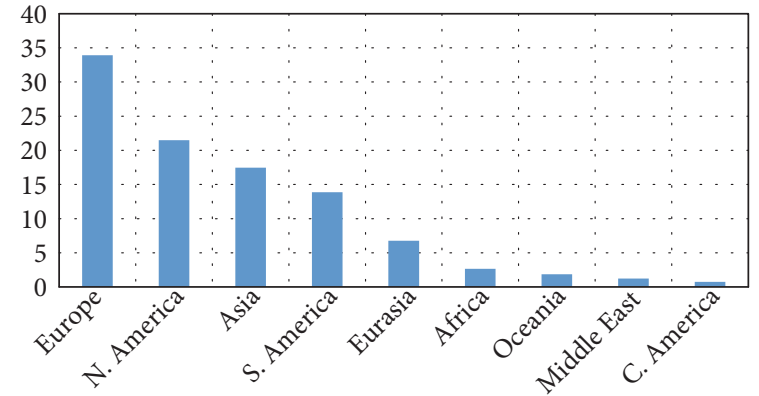

Figure 2: Percentage of world total RES installed power in 20062015, IRENA statistic 2016.

only contributions where PV-BESs are the object of an incentivisation policy, such as a feed-in tariff, are considered.

The cases of these five countries are discussed separately in the order of the total solar PV power installed; as can be seen in Figure 4, the first case is Germany as it has an installed power of $214,000 \mathrm{MW}$, and the last case is Greece with an installed power of 10,200 MW. Figure 5 reports the production of electrical energy from solar PV sources. It is interesting to note that the order of Figure 5 is identical to that of Figure 4 with the exception of the UK and Australia; the latter has a production $(13,656 \mathrm{GWh})$ that is almost double to that of the UK production $(7718 \mathrm{GWh})$ even though the installed solar PV power in Australia is approximately $16 \%$ lower than that in the UK.

Most of the contributions reported in this paper consider already existing incentive schemes; therefore, these schemes constitute the input data for the techno-economic-financial analyses together with the solar radiation, the user load profiles, and the average electricity prices. Some of these contributions propose new feed-in tariff schemes in order to promote storage technologies in general as well as integrated photovoltaic battery systems for grid-connected end users.

\section{A Brief Reference to Sizing and Integration of Photovoltaic and Batteries Systems in Distribution Grids}

In the imminent future, renewable energy sources will certainly play a key role in electricity generation; solar and wind energy sources undoubtedly have the potential to meet the energy crisis to relevant extent. Solar and wind power plants have already created favourable conditions to switch the electricity generation from large-centralized facilities to small-decentralized units, exploiting the technological development and the increasing market competitiveness in the renewable energy sectors. These small-decentralized units are the implementation of the distributed generation as cultural concept, as feasible solution for a sustainable development extended also to remote areas, and as an effective environmental impact reduction.

In the current thinking, PV power generation on rooftop is the entry-level technology suitable for a massive transition towards a low-carbon power generation, also in the buildings sector. The increase in the use of incentives 


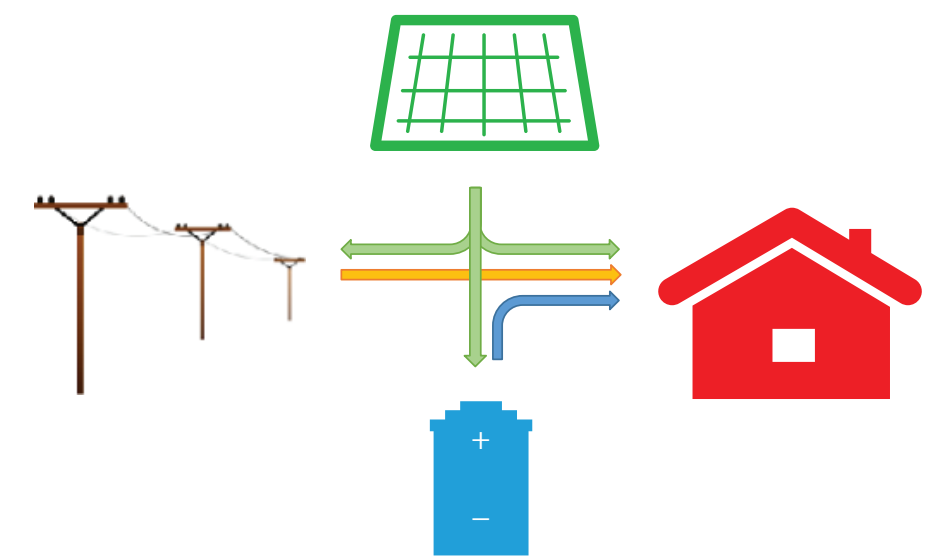

FIGURE 3: An integrated photovoltaic battery energy storage system (PV-BES).

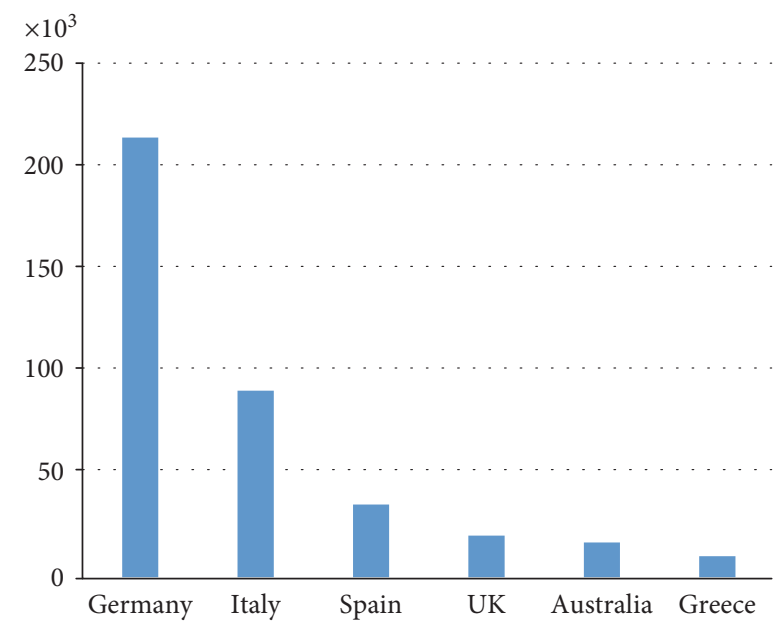

Figure 4: Solar PV installed power MW in 2006-2015, IRENA statistic 2016.

for the construction of integrated photovoltaic systems in buildings has decisively established that such distributed generation, combined with the use of microinverters, is a viable option with great growth potential [5]. Undoubtedly, the wide spread of distributed generation strongly depended on government policies to support PV systems, by credit guarantee scheme in favour of the citizen and/or granting. Today, subsidies still exist in few countries but are subject to a fast reduction; so, self-consumption may be the only way to gain financial profit from distributed generation at residential and building level. Indeed, in those countries where there are no government policies to support PV systems, no credit guarantee schemes in favour of the citizen, and no grants, the sole incentive is self-consumption; the lower is the export price for PV energy with respect the retail price, the higher is the attractiveness of self-consumption. Thanks to selfconsumption and the rapid decrease of the costs of modules and inverters, covering the roofs with PV modules remains an attractive investment, even in the absence of subsidies.

Performance of PV technology cannot be accounted for solely in terms of cost targets and energy efficiency. In this assessment, a holistic view is lacked; therefore, benefits as

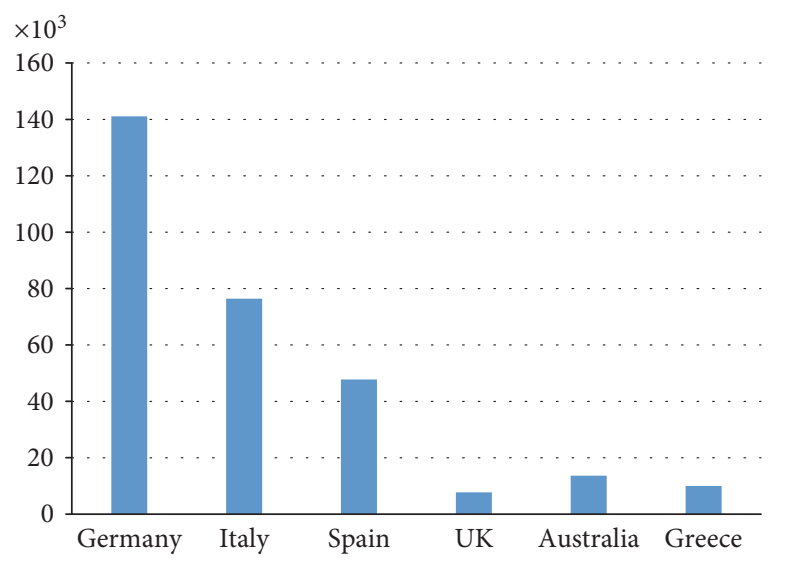

FIgURE 5: Solar PV production GWh in 2006-2015, IRENA statistic 2016.

the peak demand reduction, the improved network stability, and loss reduction are not accounted [6]. Actually, a comprehensive and holistic analysis of how the combination of influencing factors determines the economics of rooftop modules is still missing [7]. Citizens who have installed PV modules on roofs are an example of distributed power generation at residential level, but they are also carriers of important benefits for the environment and the rest of the electrical system. If properly managed, prosumers may contribute to improving the system stability and reduce overall losses $[8,9]$. On the other hand, the increasing electrification will put the reliability and stability of distribution grids under pressure. Integrating solar electricity generator at utility scaled into power networks may negatively affect the performance of the next generation of smart grids. In particular, the rapidly changing of power generated by many distributed generators is almost unpredictable; electrical storage systems like batteries are the technical trick to move problems from short term to mid term [10].

In the light of the above analyses, it is clear that distributed generation through PV plants on rooftops contributes to alleviate the overall load on LV distribution grids, the peak demand, and the power losses. Besides these benefits, new 
problems and issues arise. The LV grids, in fact, were originally designed to accommodate a unidirectional current flow, from the distribution network to consumers. With the high penetration of distributed generation, the current can reverse its direction; a possible consequence of reversal of the power flow is the occurrence of overvoltage. This is a new and unwelcome challenge for the distribution system operator, but it may be also a limitation to PV systems spread. A further limitation to such a spread may be the inability or high costs associated to the excessive generation with respect the demand; to face a surplus of generation, it is useful to mention the strengthening of the distribution networks and the widespread installation of small/limited storage systems at $\mathrm{LV}$ grid levels.

The examination of the hourly and intrahourly time series of the potential energy generation from distributed PV systems is recommended and necessary in order to obtain a proper understanding of the zonal energy balance [11]. The frequent variation of the solar radiation on PV modules and the frequent variation of speed and direction on a wind turbine make these two sources, that is, sun and wind, too intermittent and unreliable. Therefore, connecting these sources to the grid presents challenges in various technical aspects: power quality, protection, dispatching, control, and reliability. Levelling the output of PV systems and wind generators is necessary to maintain the grid stability [12]. In this regard, the adoption of energy storage systems is a feasible solution to compensate for the above-mentioned fluctuations and to meet the demand of energy during the night hours $[13,14]$. Simultaneously, implementing demand response programmes can facilitate a resolution of this issue [15]. In addition to demand response, several research contributions examine the coordination of PV battery systems with demand side management. The total number of these research contributions is considered as limited; further comparative studies are required to achieve a complete overview of these technologies and their potential [16].

The use of battery energy storage systems, integrated with the PV modules, allows to decouple the generation and the consumption of electric energy. This deferred timeline is a simple and feasible solution, useful to reduce the grid load during peak hours so to avoid the strengthening of distribution networks. Novel control strategies for battery recharge management may be developed so to achieve benefits and savings for both the distribution system operators and prosumers [17]. Scheduling the battery operation installed at the prosumer level is strongly recommended because the battery degradation has a high cost and such a cost is mainly a function of the storage system operation [18].

The effects and the actual benefits of domestic integrated PV battery systems and the effects and real benefits on the distribution and transmission grids have to be identified and analyzed. The development of strategies for the coordinated management of the grid and storage systems is a necessary step to analyze and evaluate the real potential of domestic battery storage systems as a solution to mitigate the stress on the electric power system [19]. On the other hand, the use of these hybrid energy systems looks promising because they are reliable and economical, thanks to the complementary nature of the two resources. However, at present, it is still unclear when and under what conditions the battery storage can be profitably used in residential photovoltaic systems without any political support [20-22].

As previously mentioned, self-consumption is a fundamental key for a proper evaluation of distributed generators when integrated to storage systems; scheduling of domestic loads such as washing machines, dryers, and dishwashers is an exciting opportunity to maximize self-consumption [23]. In this context, depending on the solar radiation, incentives, special discounts, and other factors, techniques for the demand side management can assist families in changing their usual habit in the electricity consumption [24]. Because these techniques use PV generation forecasting to determine the optimal loads scheduling, the greater the goodness of forecasting, the higher the savings. In case of inaccurate forecasts, errors are limited by using battery storage systems [25]. Because load profiles in commercial applications have a higher correlation with the daily solar radiation with respect to the residential applications, also the retail and commercial sectors are important sources of productivity gains and savings [26].

Finally, the introduction of electric vehicles in the home environment accentuates the "delay" between the load profile of the families and the generation profile of the PV modules [27]. Even in this case, the use of batteries seems a mandatory measure rather than an appropriate choice. Indeed, the spread of charging stations-which exploiting renewable energy sources-placed outside the home environment has increased in the recent years thanks to the use of distributed battery storage systems [28]. Although many contributions studied the integration of charging station and the utility grid, some researchers believe that none of these contributions has given due emphasis on the PV charger [29].

\section{A Brief Reference to Incentive Polices and Implementation Schemes}

In order to incentivise the adoption and use of renewable energy sources, different types of incentive mechanisms and schemes have been implemented in different countries and jurisdictions, such as feed-in tariff, quota obligation, green certificates, tendering system, and net metering.

The feed-in tariff (FIT) scheme is the most effective scheme in encouraging rapid and sustained spread of renewable energies because a feed-in tariff scheme significantly reduces the risks of investing in renewable energy technologies so that the market can grow rapidly.

There are different ways to structure an FIT scheme, each with its own strengths and weaknesses. In [30], Couture and Gagnon present seven different ways, which are not mutually exclusive, of structuring the payment of an FIT policy. These seven ways are divided into two large categories, namely those in which payment is dependent on the price of electrical energy and those that, on the contrary, remain independent of it. 
Independent market FIT policies are policies that offer a purchase guarantee and either a fixed price or a minimum price for electrical energy from renewable sources fed into the grid. Instead, market-dependent FIT policies require renewable energy developers to provide their electricity to the market, so forcing developers to a competition with other suppliers to meet market demand. These policies offer a premium price or a feed-in premium, which comes on top of the market price.

In order to avoid windfall profits when the electricity market prices rise, governments can impose caps and floors on FIT premiums. From an analysis of the marketindependent option, Couture and Gagnon highlight that the main advantage consists in the predetermined and guaranteed payment levels, which offer significant benefits including greater investment security, a more reliable and predictable revenue stream for developers, and lower overall risks. On the other hand, fixed price FITs distort competitive electricity prices because the purchase prices remain fixed regardless of the electricity market price; so, even if prices decline, RE producers will continue to receive the guaranteed prices. Moreover, fixed price FITs offer the same prices regardless of the time of day at which electricity is supplied, ignoring the prevailing electricity demand.

Couture and Gagnon analyzed the market-dependent option and highlights that the main advantage is encouraging demand sensitivity of RE producers, thus providing benefits to both grid operators and society. Indeed, producers are incentivised to supply electricity to the grid in times of high demand, when prices are the highest. In such a way, a more efficient electricity market is achieved because RE supply is encouraged at times when electricity is needed most. In addition, the premium price model could help meet peak demand especially when the spread between peak and off-peak prices is significant. However, the market-dependent option is not without disadvantages.

One disadvantage of the market-dependent option is the unpredictable electricity retail prices which create greater uncertainty for both investors and developers. This uncertainty is often an insurmountable obstacle because negative cash flows of RE projects are all concentrated at the beginning of the process to pay for technology and are amortized over periods of 15 years or more. Moreover, the reduction in market prices created by large increases in RE plants reduces appeal for investors and developers. The uncertainty of electricity retail prices is also a relevant obstacle for smaller investors who, in order to obtain project financing, need more stable and predictable revenue streams.

In [31] also, Sioshansi addresses the issue of how to incentivise the adoption of renewable energy sources and different types of incentive mechanisms commonly used in different jurisdictions. More interestingly, Sioshansi examines a problem of allocation of costs that arise following the use of distributed renewable energy (DRE) systems such as volumetric pricing.

As is well-known, residential customers pay a volumetric tariff to recover costs due to the providing energy service and due to the generation, transmission, and distribution capacity service; such a volumetric tariff mainly depends on energy consumption. Thus, for a customer who installs a PV plant, possibly integrated with a storage system, which drastically reduces electricity bought from the grid, then his payment to the utility company would be close to zero. However, the services mentioned above have to be installed and maintained to reliably serve the customer. Overall, volumetric costs determine the allocation of inefficient costs with DRE.

Furthermore, incentivisation mechanisms such as FIT worsen this inefficiency as the majority of these programmes offer incentives on the basis of energy generated by a DRE, without considering its effect on the capacity needs and costs.

\section{The Case of Germany}

Germany is notoriously one of the countries that firmly believed-and invested heavily-in the exploitation of renewables, also including technologies for energy storage on different scales. Since May 2013, the state-owned KfW bank has granted low-interest loans with an aggregate value of 163 million euros in order to promote PVBESs with a PV peak power of up to $30 \mathrm{~kW}$ which should feed a maximum $60 \%$ of installed capacity into the grid. The Federal Ministry for Economic Cooperation and Development also covers $30 \%$ of the battery storage system costs. According to a study by RWTH University, almost 34,000 PV-BESs, with an average capacity of $6 \mathrm{kWh}$, was installed by 31 January 2016. Around $27 \%$ of the installed systems are mounted with lead-acid batteries, the rest with lithium batteries. When governmental support of PV-BES battery systems was introduced in May 2013, the budget was 60 million euros; a new programme started in March 2016 with a budget of 30 million euros will run until 2018. Since 2013, prices for lithium batteries in Germany have fallen by $18 \%$ per year.

4.1. PV-BESs in Commercial Applications. The study of integrated PV-BESs on the German FIT policy in commercial applications is addressed in 2016 in [26]; in the reference, Merei et al. focus their attention in this sector in that, in their opinion, there is a significant opportunity for economic savings. The reason for this is that commercial buildings usually have ample space on their roofs for the installation of photovoltaic panels and because their load profiles have a high correlation with the generated solar energy. Therefore, the authors study the real case of a supermarket in Aachen with a yearly electricity consumption of $238 \mathrm{MWh}$. For the cost calculation, the authors consider an import price of $€ 20 \mathrm{c} / \mathrm{kWh}$, a cost of production of electrical energy from solar panels of about $€ 8-12 \mathrm{c} / \mathrm{kWh}$, and a feed-in tariff of $€ 10 \mathrm{c} / \mathrm{kWh}$.

The cost analysis for a PV system returns a cost reduction of $30 \%$ when the cheapest prices of PV systems of $€ 1200 /$ $\mathrm{kWp}$ and the lowest interest rates of $4 \%$ are considered. The cost analysis for the same PV systems discussed above but in combination with battery storage and a feed-in tariff of $€ 10 \mathrm{c} / \mathrm{kWh}$ returns no yearly cost reduction but rather leads to a rise in costs. In conclusion, battery storage increases self-consumption significantly, yet even unrealistic 
battery prices of less than $€ 200 / \mathrm{kWh}$ cannot lead to an economic solution in the considered commercial application.

4.2. PV-BESs in Residential Applications. The study of integrated PV-BES on the German FIT policy in residential applications was addressed in 2009 in [32]; in this work, Braun et al. illustrate an integrated PV-BES developed in a French-German project called Sol-ion. Considering a storage system based on lithium-ion batteries and the German Renewable Energy Sources Act (EEG) which grants selfconsumption in residential applications, the Sol-ion project proposes several models that are useful in analyzing energy flows and calculating the increase of PV self-consumption in residential PV-BESs installed in Germany and in France. The authors conclude that the adoption of the Sol-ion system is a profitable operation for a battery system price below $€ 350 / \mathrm{kWh}$.

In the reference, the authors introduce their study evaluating the reduction of the export price that occurred in 2009 from $€ 43.01 \mathrm{c} / \mathrm{kWh}$ to $€ 25.01 \mathrm{c} / \mathrm{kWh}$ for those customers that self-consume self-generated PV energy using battery storage systems. The difference of $€ 18 \mathrm{c} / \mathrm{kWh}$ is a cost which has to be compared with the import price. The German Federal Statistical Office calculated that the average electricity price in 2009 without VAT was approximately $€ 19.45 \mathrm{c} / \mathrm{kWh}$; therefore, residential customers with a Sol-ion system could save $€ 1.45 \mathrm{c} / \mathrm{kWh}$ if $100 \%$ of the self-generated PV energy is selfconsumed. Therefore, the authors calculated that residential customers with a $5 \mathrm{kWp}$ PV plant could save electricity costs up to $€ 73$ per year if $100 \%$ of local generation is consumed locally. An increase of the profit margin is achieved when an increase of electricity prices of $4 \%$ per year is considered: the saved electricity costs rise to $€ 5.66 \mathrm{c} / \mathrm{kWh}$ and $€ 283$ per year. Additionally, the regression of the reimbursement tariffs leads to an increase of the profit margin; given depression rates of $8 \%$ in 2010 and 9\% onwards, in 2012, residential customers with a Sol-ion system saved electricity costs of $€ 7.71-8.61 \mathrm{c} / \mathrm{kWh}$ and $€ 385-430$ per year. The case study considered by Braun et al. for the simulation results is a base scenario where the export price is $€ 32.77 \mathrm{c} / \mathrm{kWh}$, the self-consumption feed is $€ 19.05 \mathrm{c} / \mathrm{kWh}$, the annual increase of electricity prices is $4 \%$, and the annual consumption is 5.5 MWh. Data refer to 2012. Based on these assumptions, a Sol-ion system using lithium-ion batteries with a capacity of $11.5 \mathrm{kWh}$ and specific costs of $€ 350 / \mathrm{kWh}$ is evaluated. The numerical results demonstrate that the Sol-ion system increases self-consumption by $82 \%$ compared to that of a conventional PV system without batteries; furthermore, the breakeven is reached between the 15th and the 20th year, depending on the installation and maintenance costs.

In 2012, the study of integrated PV-BESs on a current German feed-in tariff in residential applications is the focus of [33]; Mulder et al. who affirm that since 2012, the use of lead batteries up to $5 \mathrm{kWh}$ is convenient even in the absence of subsidies, independent of an increase in the cost of electrical energy. Taking the progressive decrease of the cost of lithium batteries into consideration, the authors state that this type of technology will certainly soon be attractive. In particular, if the price of electrical energy increases by $4 \%$, then
$4 \mathrm{kWh}$ lithium batteries will already be economically advantageous in 2017, even in the absence of subsidies. The authors also present a cost-benefit analysis based on 2012 market prices and best future expectations; financial indicators such as the net present value, the internal rate of return, and the payback period were used. The numerical results reported in the paper refer to 260 combinations obtained using data from 65 households and 4 PV systems in Belgium; data measured every 15 minutes over a year.

In 2013, [21] presented a study that is very similar to Braun et al.'s 2009 study and Mulder et al.'s 2012 study. In the reference, Hoppmann et al. conclude that investing in storage batteries in Germany was economically advantageous for small systems already in 2013, investing in storage batteries in Germany was economically advantageous for small PV systems even not considering feed-in type policies. However, a possible promotional policy for battery storage systems is a valid instrument, which is only necessary in the short term. The authors create a technical-economic model and use this model to assess the viability of battery storage under eight scenarios from 2013 to 2022; each scenario is generated by varying the PV costs and the electricity prices. For each scenario, the model generates and tests more than 1400 photovoltaic battery combinations and identifies the combination with the highest net present value; the final user receives no feed-in tariff or self-consumption premium for the electricity self-produced by using the PV system. The study concludes that the economic viability of the battery storage for residential PV is particularly high in a scenario where the excess of electricity cannot be sold on the wholesale market.

A year later, in 2014, the study of integrated PV-BESs on the German FIT policy was again addressed in [34]. Like many other academics, Weniger et al. also seek to identify the storage system price at which residential PV-BESs become economically sustainable. In actual fact, Weniger et al. question which factor mainly influences the breakeven price. The results reveal that the main factor is the rate of interest, followed by the PV system price, the retail price of electricity, and the feed-in tariff. The authors consider a feed-in tariff of $€ 0.12 / \mathrm{kWh}$, an import price of $€ 0.34 \mathrm{c} / \mathrm{kWh}$, and an interest rate of $4 \%$. Based on these assumptions, investing in PV-BESs is economically interesting if the PV system price is $€ 1500 / \mathrm{kWp}$ and the battery system price is below $€ 1160 / \mathrm{kWh}$. Nevertheless, if the PV system price drops to $€ 1200 / \mathrm{kWp}$, then installing a PV-BES is a profitable operation for a battery system price below $€ 1500$ / $\mathrm{kWh}$. Weniger et al. also verified that an increase in the retail electricity price of $€ 0.08 / \mathrm{kWh}$ has a larger impact than a decrease of the feed-in tariff by the same magnitude. Therefore, they suggest evaluating the profitability of PV-BESs focusing on the future development of retail electricity prices instead of on the development of new feed-in tariffs. Moreover, in [35], Bergner et al. state that the integration of PV systems with batteries will be the most economical solution in the long-term scenario.

In 2015, Lissen et al. introduced a further contribution to the study of integrated PV-BESs on the German FIT policy [36]. In the reference, Linssen et al. conduct a techno- 
economic analysis of PV-BESs with particular attention on the influence of different consumer load profiles. Hence, the authors affirm that the use of realistic load and production profiles is mandatory in order to allow for reliable statements concerning both technical parameters and economic feasibility. Otherwise, the techno-economic analysis and cost optimization results might overestimate self-consumption and lead to an incorrect calculation of the total costs. Accordingly, the numerical results illustrated in the reference relate to temporal high-resolution consumer loads and PV production profiles; load profiles are three at all. Profile 1 is the German standard load profile used by German utilities as a representative load profile for consumer groups. Profile 2 is an average profile of five single family houses usually used as a reference profile for combined heat and power systems, whereas profile 3 is a synthetic load profile generated by a simulation tool.

The PV profile is the measured profile of a $5.8 \mathrm{kWp} \mathrm{PV}$ system in 2012 with a 5-minute resolution; the yearly electricity generation returned by such a plant is $1010 \mathrm{kWh} / \mathrm{kWp}$ representing a typical value for central Germany. The PV system price is assumed as being $€ 1640 / \mathrm{kWp}$. The storage system is mounted with lithium-ion batteries; the depth of discharge is $100 \%$, the efficiency is $95 \%$, and the cycle lifetime is 6200 with a degradation of $0.4 \%$ per year. The storage system price is assumed as being $€ 1000 / \mathrm{kWh}$, exclusive of VAT. Further economic parameters are a feed-in-tariff of $€ 13.28 \mathrm{c} / \mathrm{kWh}$, an import price of $€ 29 \mathrm{c} / \mathrm{kWh}$, an interest rate of $4 \%$, and an electricity price increasing by $2.5 \%$ per year. Numerical results show that the optimal cost of the integrated PV-BES increases from profile 1 to profile 3 due to different self-consumption levels. In particular, profile 3 , which is considered as being the most realistic one, leads to the lowest value of selfconsumption. Moreover, the break-even price for the integrated system is about $€ 900 / \mathrm{kWh}$ without a battery storage support scheme and about $€ 1200 / \mathrm{kWh}$ when considering the German support scheme. Linssen et al. conclude their study underlining that the individual taxation of revenues can significantly lower the break-even costs.

\section{The Case of Italy}

In 2005, Italy introduced its first incentivisation policy for PV plants based on a FIT scheme by means of a ministerial decree, which made available a first incentivisation budget known as the "Primo Conto Energia." From 2005 to 2012, the incentivisation payment mechanism changed four times, and in 2012, a ministerial decree made the fifth and final incentivisation budget for PV systems available, the socalled “Quinto Conto Energia.” In July 2013, after about eight years of incentives, there were approximately 500,000 working incentivised plants; $10 \%$ of the plants started functioning in June 2012. By the end of 2014, there was an installed power of approximately 18 million $\mathrm{kW}$. Today in Italy, all residential users can install batteries. In order to do so, the user must simply make a new connection request of the storage system to the state-owned company GSE. The storage system can either be integrated or not with a production plant; it can feed energy stored in the battery pack to the grid and can charge the batteries from the grid. In the case of systems with batteries with a bidirectional convertor, where batteries can also charge using energy from the grid, these can be integrated with photovoltaic systems without losing the incentive as long as bidirectional electric meters have been installed. Nowadays, the only special term conceded to the installation of batteries is tax deduction equal to $50 \%$ of the investment costs to be spread over 10 years; it is allowed in the case of restructuring and building energy saving works.

An analysis of the costs/benefits of PV-BES for domestic users is reported in [37]; the analysis considers real electrical energy consumption data for approximately 400 domestic clients spread over the Italian territory as well as real data of photovoltaic production for Northern, Central, and Southern Italy. For each domestic client, the PV plant is dimensioned so that it generates the annual energy consumption of the client, which is approximately $3700 \mathrm{kWh}$; the battery storage system has a discharge yield of $80 \%$ and is dimensioned to maximize self-consumption. The result presented in the reference consists of a further saving of approximately 150 euros for an existing photovoltaic plant incentivised by the feed-in scheme and a saving of approximately 170 euros in the case of a new nonincentivised plant. The calculated annual benefit is estimated net of costs of the initial investment.

An analysis of the costs/benefits of PV-BES for an Italian Public Administration connected to medium voltage grid is reported in [38]; in the reference, Burgio et al. propose a novel scheme for an FIT policy to favour the adoption of PV-BESs by means of a constant tariff which exclusively rewards self-consumption. The generation price and the export price are both neglected. An optimization problem jointly scales the PV and the BESs considering actual data obtained measuring load consumptions each 15 minutes throughout 2011. The objective function is the sum of three terms, that is, saving, subsidy, and costs; saving is defined as the difference between the electric bill with and without the combined PV-BES, subsidy represents the money that the end user receives due to the FIT policy, and costs is the sum of the instalments for both the PV and the BESs. The feed-in tariff is in the set $€ 0.05, € 0.10, € 0.15, € 0.20, € 0.25$, and $€ 0.30 / \mathrm{kWh}$. The optimal solution consists of a PV plant of $30 \mathrm{kWp}$ and a battery storage system of $25 \mathrm{~kW} / 50 \mathrm{kWh}$. The cash flow analysis highlights that for feed-in tariffs lower than $€ 0.2274 \mathrm{c} / \mathrm{kWh}$, there is a requirement for additional financial resources. The authors also evaluated the impact of the PV-BES on load profiles by calculating the frequencies of energy measurements during 2011. In particular, the recurrence of the measurement $0 \mathrm{kWh}$ (i.e., full self-sufficiency) is $0 \%$ without the PV-BES; it increases to $7 \%$ when a PV system is adopted and it further increases to $19.02 \%$ when a storage system is also adopted.

The economic viability of a feed-in tariff scheme that solely rewards self-consumption to promote the use of PVBES is studied in [39]; in the reference, Burgio et al. use an optimization problem so to determine the incentive and the size of the PV-BES. The incentive was calculated so that the yearly subsidy equals to the difference between the instalments paid for the PV-BES and the savings obtained from 
the electricity bill. The size was calculated so that the percentage of self-produced energy is at least $50 \%$ and the percentage of self-consumed energy is at least $80 \%$. The optimization problem was applied to a real case; measured values of temperature, irradiation, energy consumption and electricity prices were considered from 2011 to 2015. The numerical results reported in the reference demonstrated that the feed-in tariff scheme for a PV-BES is feasible and advantageous: for the case study, the electricity bill in 2011 was reduced by $49.56 \%$. Moreover, the yearly subsidy is lower than the instalments paid for the PV-BES; therefore, a positive socioeconomic impact is achieved. Because the movement in the electricity prices is a crucial point in the economic evaluation of a PV-BES, the optimal solution was studied in the years from 2012 to 2015 so to evaluate the possible consequences of the collapse in electricity peak-load prices occurred at the end of 2013. The numerical results show that the PV-BES allows a reduction of the electricity bill also in the presence of this radical change in electricity prices. In particular, the reduction equals to $44.98 \%$ when the PV-BES is adopted, whereas it equals to $33.65 \%$ when only the photovoltaic system is adopted.

\section{The Case of Spain}

In Spain, the PV support policy started in 1998 with the publication of the Royal Decree (RD) 2818/1998, and the conditions were improved some years after with the publication of the RD 436/2004 and RD 661/2007. The conditions and premium were greatly modified with the RD 1578/2008. The support mechanism for PV systems gave the producers the possibility to choose whether to sell the electricity under the FIT tariff or whether to sell the electricity in the free market, taking advantage of a premium above the market price. The FIT policy granted producers for an undefined number of years; a reduction was expected after 25 years [40, 41].

Furthermore, the Royal Decree was stated the impossibility of integrating the PV systems with any storage system; such a prohibition has remained valid up to 2015. In 2012, the PV support policy was suspended with the publication of the Royal Decree 1/2012; one year later, the Royal Decree-Law 9/2013 lowered the grants of FITs retroactively.

In 2015, the Royal Decree 900/2015 introduced a selfconsumption policy. This Decree distinguishes two types of customer with self-consumption: Type 1-Supply with self-consumption, and Type 2-Generation with selfconsumption. Type 1 includes facilities and end users with an installed power no larger than $100 \mathrm{~kW}$; the surplus of generated electricity fed into the grid is not remunerated because the export price is set equal to zero. Type 2 includes production facilities signed in the "Registro administrativo de instalaciones de Produción de Energía” and with an installed power larger than $100 \mathrm{~kW}$. The surplus of generated electricity fed into the grid is remunerated.

The Royal Decree 900/2015 also stated that all customers which adhere to any self-consumption policies, that is, all customers who adopt a PV system integrated with battery storage system device are subjected to a new fee, known in Spain as" Impuesto al sol" or "solar tax." Such a new fee is a distribution and transport grid access fee required in order to ensure technical and economic sustainability of the grid. For instance, the most of end users connected to the lowvoltage distribution grid in Spain with an installed power no larger than $10 \mathrm{~kW}$ have to pay the $2.0 \mathrm{~A}$ tariff which consist of $€ 0.049033$ for each self-consumed kWh.

As expectable, the widespread opinion about solar tax in Spain is definitely negative. In particular, the Spanish solar PV association affirms that, far from encouraging self-consumption, distributed generation, and use of renewable energies, this fee discourages the development of electric self-consumption. Moreover, the association underlines that, due to this unjustified tax, the self-consumers will pay much money for the power system maintenance than the other users although the self-consumers use the power system the least.

\section{The Case of the United Kingdom}

The study of integrated PV-BESs on the United Kingdom FIT policy is addressed in [42]; McKenna et al. state that the PV-BES combination in the UK is not a convenient operation as, even if there is a feed-in tariff, there is no case of financial convenience in adopting lead batteries. Such a conclusion is valid even if considering ideal batteries without leaks and with an optimistic life expectancy.

Given an exchange rate GBP/EUR of 1.235, the UK feedin tariff consists of a generation price of $21.0 \mathrm{p} / \mathrm{kWh}$ (about $€ 25.93 \mathrm{c} / \mathrm{kWh}$ ) and an export price of $3.2 \mathrm{p} / \mathrm{kWh}$ (about $€ 3.95 \mathrm{c} / \mathrm{kWh}$ ) paid for exported units. Assuming an import price of $11.8 \mathrm{p} / \mathrm{kWh}$ (about $€ 14.57 \mathrm{c} / \mathrm{kWh}$ ), the export/import price ratio is $11.8 / 3.2=3.69$. The authors used 5 minutes of recorded data on 37 domestic dwellings with installed PV modules; the sizes of PV systems range between $1.5 \mathrm{~kW}$ peak and $3.29 \mathrm{~kW}$ peak. The battery is charged using surplus PV generation and is discharged during the evening and at night. The authors calculated that benefits amount to about $£ 30 /$ year (approximately $€ 37.05 / \mathrm{kWh}$ ) for the larger combination PV-BES. Such a low value is mainly due to battery inefficiency. Indeed, bill savings increase up to $£ 110 /$ year (about €135.85/year) when assuming lossless batteries and maintenance and installation costs are ignored.

Considering a theoretical maximum benefit of $8.6 \mathrm{p} / \mathrm{kWh}$ (about $€ 10.62 \mathrm{c} / \mathrm{kWh}$ ) of otherwise exported electricity and a modest discount factor of $4 \%$ over 20 years, the target upfront capital cost for the battery system to break even is $£ 707$ (about $€ 873.14$ ). Since the cheapest lead-acid battery system has an equivalent up-front capital cost of $£ 3296$ (about $€ 4070.56$ ), there is no economic case and specific commercial opportunity, even for idealised lossless batteries with optimistic lifetimes. The financial losses approach $£ 1000$ /year (about $€ 1235$ ) for a 570 Ah battery storage system integrated to a $3.29 \mathrm{kWp}$ PV system when realistic efficiencies and lifetimes are accounted for.

Lastly, McKenna et al. state that there is no case of economic convenience in adopting lead batteries even for the case of Germany and the Australian states of Queensland, Victoria, and Western Australia. The reason is that the solar resource in these countries is not dissimilar to that of the UK 
and the import/export price ratio for Germany (2.14) and for the Australian states (3.13) are lower than those for the UK (3.69).

\section{The Case of Australia}

Energy storage is one of the most critical topics facing energy utilities; currently, Australia is one of the top five distributed energy storage markets in the world. In 2015, the Australian Energy Storage Council (ESC) focused on laying the foundations for a successful long-term energy storage industry. Both the industry and the government worked together to develop standards and guidelines in order to ensure safe and high-quality storage products. They have also invested a considerable amount of time in providing clear information to consumers. Over 1.5 million dwellings in Australia have rooftop PVs; for those living in New South Wales, the generation price is $\$ 0.60 \mathrm{c} / \mathrm{kWh}$ whereas the export price is about $\$ 0.06 \mathrm{c} / \mathrm{kWh}$. The Australian ESC has estimated that two-thirds of daytime solar generation are delivered to the grid. These plants are the expected results to incentive policies; today, these plants have paid off well. However, the incentive policies in New South Wales, Victoria, and South Australia are coming to an end, and therefore, the only right choice for residential customers is to install a battery to store excess generation during daytime and make it available at night-time.

The study of integrated PV-BESs along with two proposals of new FIT schemes in Australia is presented in [43, 44]; Ratnam et al. and Weller et al. proposed an optimization-based approach to scheduling residential battery storage with solar PV. The aim is to maximize the electricity generation in order to achieve financial benefits for residential customers and simultaneously alleviate the utility burden associated with peak demand and reverse power flow.

The financial benefits derived from a number of possible FIT schemes proposed by the authors are explored in detail; moreover, concrete examples of two FIT schemes commonly used in Australia are also investigated. One of the FIT schemes proposed by Ratnam et al. consist of a generous constant FIT of $\$ 0.4 / \mathrm{kWh}$; such a value is higher than peak timeof-use billing but lower than the FIT offered in 2010 by North South Wales which paid a generation price of $\$ 60 \mathrm{c}$. In the authors' study, each residential customer has a Home Energy Management system similar to the low-cost smartbox presented in [45]. One day in advance, the home energy management system forecasts the residential load and PV generation; it receives the electricity prices for energy delivered to and from the grid and receives existing additional incentives and then runs the optimization-based algorithms to schedule the battery storage.

Ratnam et al. study 145 residential users with a PV system and batteries; they considered measured load and generation profiles over one year. These residential customers were randomly selected from customers located in the low voltage Australian distribution network, operated by the Ausgrid distributor; the network includes load centers in Sydney and regional New South Wales. The battery capacity is initially fixed to $10 \mathrm{kWh}$; subsequently, it varies within the range $0 \mathrm{kWh}$ and $30 \mathrm{kWh}$. Thanks to the quadratic programmebased minimization of the energy supplied by, or to, the grid proposed by the authors, the PV-BES combination allows for an overall average saving of between $\$ 350 / \mathrm{yr}$ and $\$ 100 /$ yr per residential customer.

\section{The Case of Greece}

There are thousands of Greek islands, yet only two hundred of them are inhabited; most of them are off-grid areas, powered by diesel generators. Therefore, Greek islands represent a unique opportunity for the integration of renewable energy sources and battery storage. The size of these generators must meet the peak demand, but their operation rarely generates the peak power; often, their diurnal operation is highly variable and fluctuates in accordance with the variable demand. Moreover, diesel generators require fuel imports by ship; naval transport is costly and leads to security risks. Therefore, energy storage systems might eliminate or drastically reduce reliance on diesel supplies.

The case of many Greek islands is studied in [46]; Krajačić et al. propose feed-in tariff schemes for different energy storage systems such as pumped hydro, hybrid wind pumped hydro, hydrogen, and combined PV-BESs. As an example, the techno-economic analysis of a FIT policy to promote the adoption of PV-BESs is performed considering the case study of the island of Corvo. The island has about 400 inhabitants; the yearly electricity demand is approximately $1086 \mathrm{MWh}$ with a load peak of $204 \mathrm{~kW}$. Now, two diesel generators of $120 \mathrm{~kW}$ and two of $160 \mathrm{~kW}$ serve the island. In order to calculate the subsidy for remunerating the adoption of batteries along with PV modules, the authors estimate the fuel savings achieved during operation thanks to the adoption of batteries. For a battery capacity up to $40 \mathrm{kWh}$ mounted with a $4 \mathrm{~kW}$ inverter, the proposed remuneration scheme is a fixed tariff of $€ 53.8 / \mathrm{kWh}$ multiplied by battery capacity. Further remuneration schemes are also proposed for higher values of battery and inverter capacity, at different penetration levels.

\section{Conclusion}

The paper presented a review on the recent developments of photovoltaics integrated with battery storage system and related feed-in tariff policies in the regulatory context of Germany, Italy, Spain, the United Kingdom, Australia, and Greece. The attention was focused on those integrated photovoltaic battery systems subject to incentivisation policies. The paper showed that the self-consumption is the key factor for the actual incentivisation policies; moreover, the paper confirmed that the feed-in tariff scheme is still the most effective and widely considered scheme for promoting the integration of storage batteries to existing or new photovoltaic systems. The contributions mentioned in the paper agree with each other about the adoption of integrated photovoltaic battery systems; these contributions show a positive scenario and a clear economic advantage in adopting such systems if the storage technology is lithium-ion batteries. 
Germany confirms being one of the countries that firmly believes and invests in renewables and storage; a new programme for promoting the adoption of batteries started in March 2016 with a budget of 30 million euros. In the paper, studies of PV-BESs on the German FIT policy in commercial and residential applications were reported. For commercial applications, battery storage increases self-consumption significantly, yet even unrealistic battery prices of less than $€ 200 / \mathrm{kWh}$ cannot lead to an economic solution. For the residential applications, the use of lead batteries up to $5 \mathrm{kWh}$ is convenient since about four or five years, even in the absence of subsidies and independently of an increase in the cost of electrical energy. Other studies conclude that the adoption of PV-BESs is a profitable operation for a battery system price below $€ 350 / \mathrm{kWh}$ when lithium-ion batteries substitute for the lead ones.

Italy seems weighed down by the significant incentive policy of systems for the exploitation of renewable sources started in 2005 and lasted eight years. To date, Italy only supports the installation of batteries with a special term consisting in a tax reduction of the $50 \%$ of the batteries costs to be spread in 10 years. The paper reported a costs/benefits analysis of PV-BES considering real electrical energy consumption data for approximately 400 domestic clients spread over the Italian territory. A saving of approximately 150 euros for existing PV plants already incentivised by the feed-in scheme is achieved thanks to the adoption of batteries; this saving increases to approximately 170 euros in the case of a new nonincentivised PV plants. The paper also reported the economic viability of a novel feed-in tariff scheme that solely rewards self-consumption; such a scheme is applied to an existing Italian Public Administration and allows a 50\% self-generation, an $80 \%$ self-consumption, and a $45 \%$ reduction of the electricity bill.

Spain is still experiencing the legacies of past incentive policies but, with great strength and motivation, this country has recently introduced a self-consumption support policy. Unfortunately, the simultaneously introduction of the socalled "solar tax" leads to the wide disapproval of customers and industry trade associations in the recent Spanish selfconsumption support policies. Due to solar tax, the most of end users connected to the low-voltage distribution grid with an installed power no larger than $10 \mathrm{~kW}$ have to pay $€ 0.049$ for each self-consumed kWh.

The United Kingdom has an unpromising legislative landscape at the moment; no incentives to companies and no subsidies to households are offered to install energy storage. But an optimistic feeling characterizes the UK storage industry; such a feeling contrasts the conclusions of the recent research contributions which affirm that, to date, the PV-BES combination in the UK is not a convenient operation as there is no case of financial convenience in adopting cost-effective and ideal lead-acid batteries.

Australia is one of the top five distributed energy storage markets in the world; the major effort in 2015 of the Australian Energy Storage Council has been lay the foundations for a successful energy storage industry in the long term. In June 2016, the Australian Capital Territory board launched a proposal for the Next Generation Energy Storage Grants; the government has allocated $\$ 2$ million in funding five companies to install solar storage homes and commercial buildings in Canberra. This paper reported the financial benefits derived from a number of possible FIT schemes proposed for this country; among them, the most attractive scheme is a generous constant FIT, higher than peak time-of-use billing but lower than the FIT offered in 2010. A case study of 145 residential customers with a PV-BES demonstrates that the PV-BES combination allows for an overall average saving of between $\$ 100 / y r$ and $\$ 350 / y r$ per residential customer.

Greece is currently experiencing a phase of difficulties and uncertainties, a national economy devoted to address crucial issues such as employment and welfare; as a result, implementing policies aimed at encouraging the adoption of PV-BES is not a priority to date. Despite this, Greece maintains a high interest in PV-BESs because Greek islands are thousands and diesel generators power most of them. Therefore, battery storage represents a unique opportunity for the effective integration of renewable energy sources in these off-grid areas. The techno-economic analysis of a FIT policy to promote the adoption of PV-BESs in the island of Corvo was presented in the paper.

\section{Conflicts of Interest}

The authors declare that they have no conflicts of interest.

\section{References}

[1] International Energy Agency (IEA), World Energy Outlook 2015, 2015.

[2] International Renewable Energy Agency (IRENA), Smart Grids and Renewables. A Cost-Benefit Analysis Guide for Developing Countries, 2015.

[3] A. Pyrgou, A. Kylili, and P. A. Fokaides, "The future of the feed-in tariff (FiT) scheme in Europe: the case of photovoltaics," Energy Policy, vol. 95, pp. 94-102, 2016.

[4] R. Darwall, How Renewable Subsidies Destroyed the UK Electricity Market. Central Planning with Market Features, 2015.

[5] H. P. Ikkurti and S. Saha, "A comprehensive techno-economic review of microinverters for building integrated photovoltaics," Renewable and Sustainable Energy Reviews, vol. 47, pp. 997-1006, 2015.

[6] S. F. Baborska-Narozny and F. J. Ziyad, "User learning and emerging practices in relation to innovative technologies: a case study of domestic photovoltaic systems in the UK," Energy Research \& Social Science, vol. 13, pp. 24-37, 2016.

[7] T. Lang, E. Gloerfeld, and B. Girod, “Don't just follow the sun a global assessment of economic performance for residential building photovoltaics," Renewable and Sustainable Energy Reviews, vol. 42, pp. 932-951, 2015.

[8] A. Colmenar-Santos, S. Campíñez-Romero, C. Pérez-Molina, and M. Castro-Gil, "Profitability analysis of grid-connected photovoltaic facilities for household electricity self-sufficiency," Energy Policy, vol. 51, pp. 749-764, 2012.

[9] P. Kästel and B. Gilroy-Scott, "Economics of pooling small local electricity prosumers-LCOE \& self-consumption," Renewable and Sustainable Energy Reviews, vol. 51, pp. 718729, 2015. 
[10] S. Koohi-Kamali, N. A. Rahim, and H. Mokhlis, "Smart power management algorithm in microgrid consisting of photovoltaic, diesel, and battery storage plants considering variations in sunlight, temperature, and load," Energy Conversion and Management, vol. 84, pp. 562-582, 2014.

[11] L. Ramirez Camargo, R. Zink, W. Dorner, and G. Stoeglehner, "Spatio-temporal modeling of roof-top photovoltaic panels for improved technical potential assessment and electricity peak load offsetting at the municipal scale," Computers, Environment and Urban Systems, vol. 52, pp. 58-69, 2015.

[12] S. Shivashankar and M. Karimi, "Mitigating methods of power fluctuation of photovoltaic (PV) sources - a review," Renewable and Sustainable Energy Reviews, vol. 59, pp. 1170-1184, 2016.

[13] M. Bortolini, M. Gamberi, and A. Graziani, "Technical and economic design of photovoltaic and battery energy storage system," Energy Conversion and Management, vol. 86, pp. 81-92, 2014.

[14] F. Marra and G. Yang, "Chapter 10 - decentralized energy storage in residential feeders with photovoltaics," Energy Storage for Smart Grids, vol. 2015, pp. 277-294, 2015.

[15] D. Vanhoudt, D. Geysen, B. Claessens, F. Leemans, L. Jespers, and J. Van Bael, “An actively controlled residential heat pump: potential on peak shaving and maximization of self-consumption of renewable energy," Renewable Energy, vol. 63, pp. 531-543, 2014.

[16] R. Luthander, J. Widén, D. Nilsson, and J. Palm, "Photovoltaic self-consumption in buildings: a review," Applied Energy, vol. 142, pp. 80-94, 2015.

[17] J. Li and M. A. Danzer, "Optimal charge control strategies for stationary photovoltaic battery systems," Journal of Power Sources, vol. 258, pp. 365-373, 2014.

[18] M. Gitizadeh and H. Fakharzadegan, "Battery capacity determination with respect to optimized energy dispatch schedule in grid-connected photovoltaic systems," Energy, vol. 65, pp. 665-674, 2014.

[19] J. Moshövel, K. P. Kairies, D. Magnor et al., "Analysis of the maximal possible grid relief from PV-peak-power impacts by using storage systems for increased self-consumption," Applied Energy, vol. 137, pp. 567-575, 2015.

[20] A. Bayod-Rújula, M. E. Haro-Larrodé, and A. MartínezGracia, "Sizing criteria of hybrid photovoltaic-wind systems with battery storage and self-consumption considering interaction with the grid," Solar Energy, vol. 98, pp. 582-591, 2013.

[21] J. Hoppmann, J. Volland, T. S. Schmidt, and V. H. Hoffmann, "The economic viability of battery storage for residential solar photovoltaic systems - a review and a simulation model," Renewable and Sustainable Energy Reviews, vol. 39, pp. 11011118, 2014.

[22] E. Waffenschmidt, "Dimensioning of decentralized photovoltaic storages with limited feed-in power and their impact on the distribution grid," Energy Procedia, vol. 46, pp. 88-97, 2014.

[23] J. Widén, "Improved photovoltaic self-consumption with appliance scheduling in 200 single-family buildings," Applied Energy, vol. 126, pp. 199-212, 2014.

[24] O. Motlagh, P. Paevere, T. S. Hong, and G. Grozev, "Analysis of household electricity consumption behaviours: impact of domestic electricity generation," Applied Mathematics and Computation, vol. 270, pp. 165-178, 2015.
[25] D. Masa-Bote, M. Castillo-Cagigal, E. Matallanas et al., "Improving photovoltaics grid integration through short time forecasting and self-consumption," Applied Energy, vol. 125, pp. 103-113, 2014.

[26] G. Merei, J. Moshövel, D. Magnor, and D. U. Sauer, "Optimization of self-consumption and techno-economic analysis of PV-battery systems in commercial applications," Applied Energy, vol. 168, pp. 171-178, 2016.

[27] J. Munkhammar, P. Grahn, and J. Widén, “Quantifying selfconsumption of on-site photovoltaic power generation in households with electric vehicle home charging," Solar Energy, vol. 97, pp. 208-216, 2013.

[28] J. P. Torreglosa, P. García-Triviño, L. M. Fernández-Ramirez, and F. Jurado, "Decentralized energy management strategy based on predictive controllers for a medium voltage direct current photovoltaic electric vehicle charging station," Energy Conversion and Management, vol. 108, pp. 1-13, 2016.

[29] A. R. Bhatti, Z. Salam, M. Junaidi, B. A. Aziz, K. P. Yee, and R. H. Ashique, "Electric vehicles charging using photovoltaic: status and technological review," Renewable and Sustainable Energy Reviews, vol. 54, pp. 34-47, 2016.

[30] T. Couture and Y. Gagnon, "An analysis of feed-in tariff remuneration models: implications for renewable energy investment," Energy Policy, vol. 38, no. 2, pp. 955-965, 2010.

[31] R. Sioshansi, "Retail electricity tariff and mechanism design to incentivize distributed renewable generation," Energy Policy, vol. 95, pp. 498-508, 2016.

[32] M. Braun, K. Büdenbender, and D. Magnor, "Photovoltaic self-consumption in Germany using lithium-ion storage to increase self-consumed photovoltaic energy," in Proc. 24th European Photovoltaic Solar Energy Conference and Exhibition, Hamburg, Germany, 2009.

[33] G. Mulder, D. Six, B. Claessens, T. Broes, N. Omar, and J. V. Mierlo, "The dimensioning of PV-battery systems depending on the incentive and selling price conditions," Applied Energy, vol. 111, pp. 1126-1135, 2013.

[34] J. Weniger, T. Tjaden, and V. Quaschning, "Sizing of residential PV battery systems," Energy Procedia, vol. 46, pp. 78-87, 2014.

[35] J. Bergner, J. Weniger, and T. Tjaden, "Economics of residential PV battery Systems in the Self-Consumption Age," in Proc. 29th European Solar Energy Conference and Exhibition (EUPVSEC), pp. 3871-3877, Amsterdam, Netherlands, 2014.

[36] J. Linssen, P. Stenzel, and J. Fleer, "Techno-economic analysis of photovoltaic battery systems and the influence of different consumer load profiles," Applied Energy, vol. 185, pp. 20192025, 2017.

[37] Ricerca sistema Energetico (RSE), I Sistemi Di Accumulo Nel Settore Elettrico, 2015, (In Italian).

[38] A. Burgio, G. Belli, G. Brusco, D. Menniti, A. Pinnarelli, and N. Sorrentino, "A novel scheme for a feed-in tariff policy to favorite photovoltaic and batteries energy storage systems for gridconnected end-user," International Review on Modelling and Simulations, vol. 6, no. 4, pp. 1123-1132, 2013.

[39] A. Burgio, G. Brusco, D. Menniti, A. Pinnarelli, and N. Sorrentino, "The economic viability of a feed-in tariff scheme that solely rewards self-consumption to promote the use of integrated photovoltaic battery systems," Applied Energy, vol. 183, pp. 1075-1085, 2016.

[40] L. M. Ayompe and A. Duffy, "Feed-in tariff design for domestic scale grid-connected PV systems using high resolution 
household electricity demand data," Energy Policy, vol. 61, pp. 619-627, 2013.

[41] C. Gallego-Castillo and M. Victoria, "Cost-free feed-in tariffs for renewable energy deployment in Spain," Renewable Energy, vol. 81, pp. 411-420, 2015.

[42] E. McKenna, M. McManus, S. Cooper, and M. Thomson, "Economic and environmental impact of lead-acid batteries in grid-connected domestic PV systems," Applied Energy, vol. 104, pp. 239-249, 2013.

[43] E. L. Ratnam, S. R. Weller, and C. M. Kellett, "Residential load and rooftop PV generation: an Australian distribution network dataset," International Journal of Sustainable Energy, vol. 6451, pp. 1-20, 2015.

[44] S. R. Weller, E. L. Ratnam, and C. M. Kellett, "An optimizationbased approach to scheduling residential battery storage with solar PV: assessing customer benefit," Renewable Energy, vol. 75, pp. 123-134, 2015.

[45] D. Menniti, G. Barone, G. Brusco, A. Burgio, A. Pinnarelli, and N. Sorrentino, "A smartbox as a low-cost home automation solution for prosumers with a battery storage system in a demand response program," in Proc. 16th International Conference on Environment and Electrical Engineering (EEEIC), Florence, Italy, 2016.

[46] G. Krajačić, N. Duić, A. Tsikalakis et al., "Feed-in tariffs for promotion of energy storage technologies," Energy Policy, vol. 39, no. 3, pp. 1410-1425, 2011. 

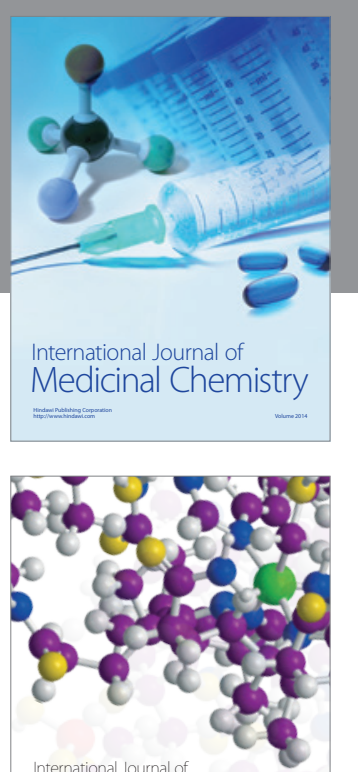

Carbohydrate Chemistry



The Scientific World Journal
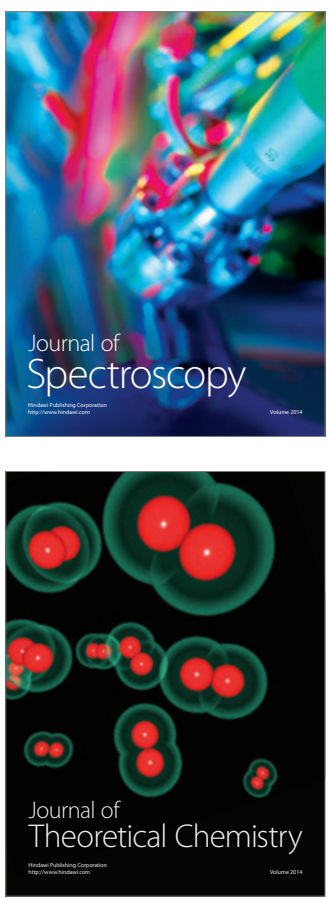
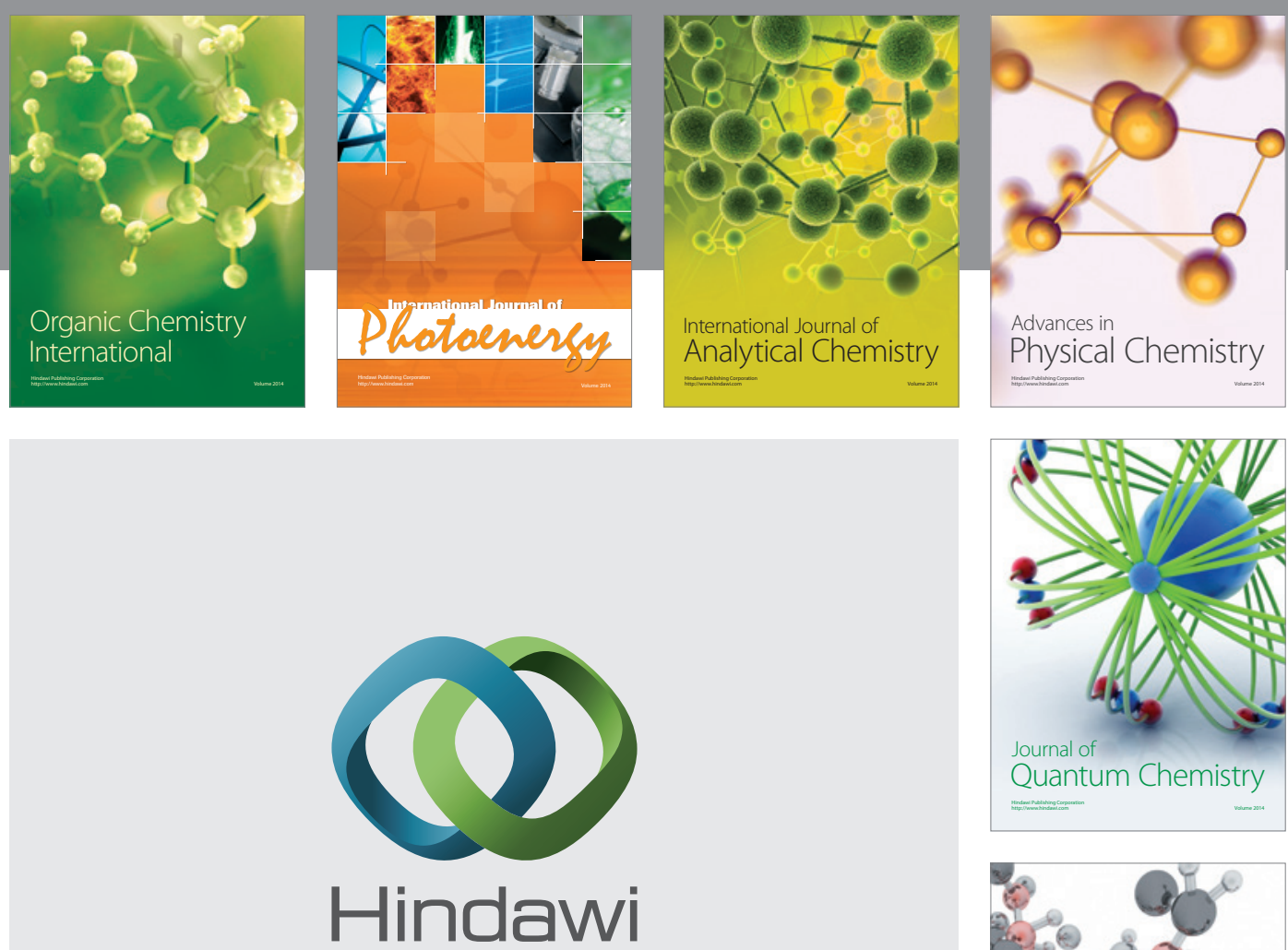

Submit your manuscripts at

https://www.hindawi.com

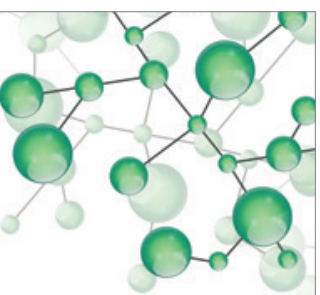

International Journal of

Inorganic Chemistry
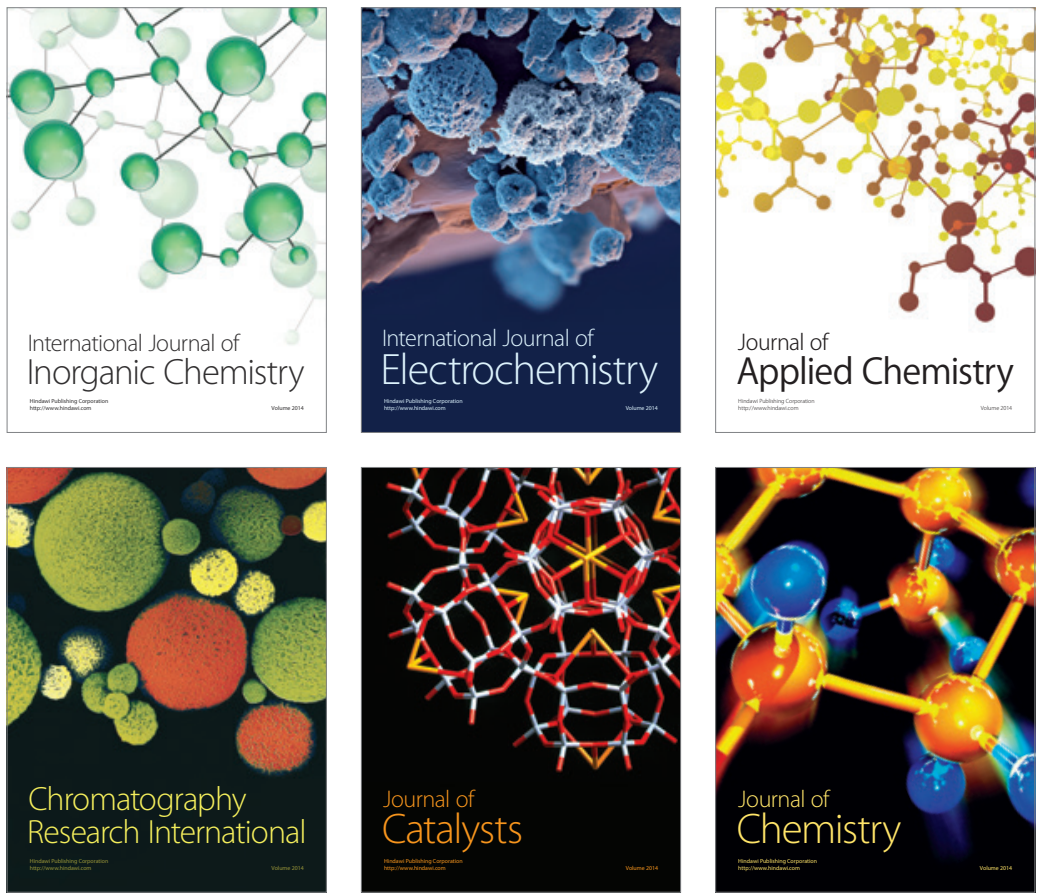

Journal of

Applied Chemistry
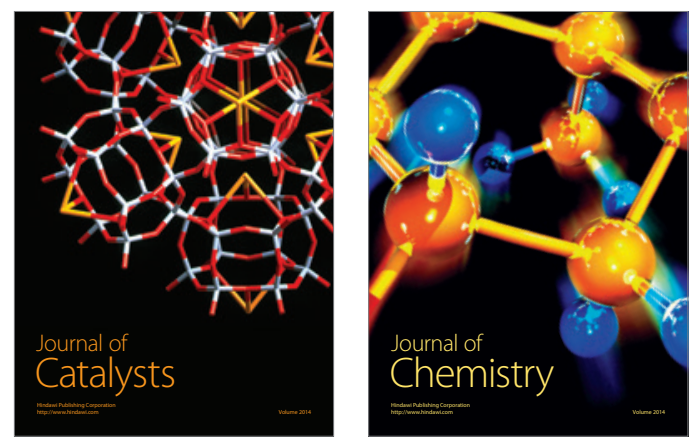
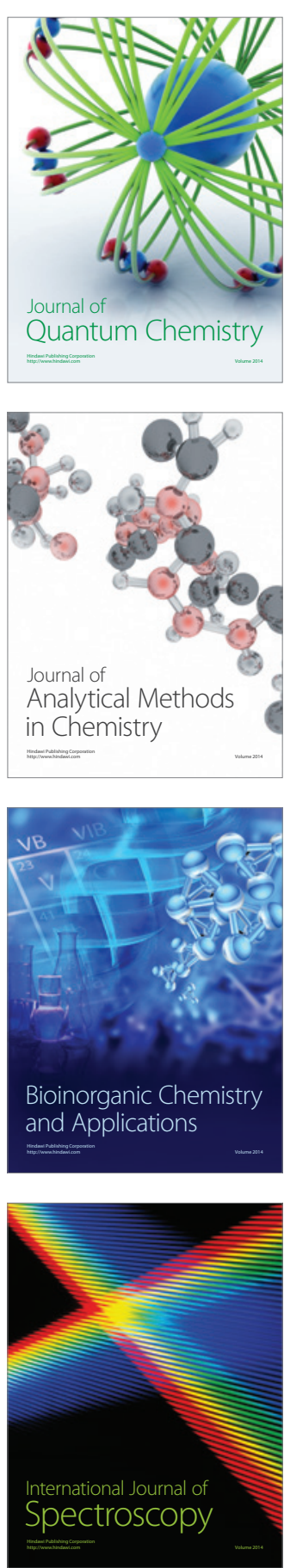